\title{
Survival in incident and prevalent cohorts of patients with pulmonary arterial hypertension
}

\author{
M. Humbert, O. Sitbon, A. Yaïci, D. Montani, D.S. O'Callaghan, X. Jaïs, F. Parent, \\ L. Savale, D. Natali, S. Günther, A. Chaouat, F. Chabot, J-F. Cordier, G. Habib, \\ V. Gressin, Z-C. Jing, R. Souza and G. Simonneau on behalf of the French Pulmonary \\ Arterial Hypertension Network
}

ABSTRACT: Pulmonary arterial hypertension (PAH) is a progressive, fatal disease.

We studied 674 consecutive adult patients who were prospectively enrolled in the French PAH registry (121 incident and 553 prevalent cases). Two survival analyses were performed. First, the cohort of 674 patients was followed for 3 yrs after study entry and survival rates described. Then, we focused on the subset with incident idiopathic, familial and anorexigen-associated PAH $(n=56)$ combined with prevalent patients who were diagnosed $<3$ yrs prior to study entry $(n=134)$.

In the cohort of 674 patients, 1-, 2-, and 3-yr survival rates were $87 \%$ (95\% Cl 84-90), 76\% (95\% $\mathrm{Cl} 73-80$ ), and $67 \%(95 \% \mathrm{Cl} 63-71)$, respectively. In prevalent idiopathic, familial and anorexigenassociated PAH, 1-, 2-, and 3-yr survival rates were higher than in incident patients $(p=0.037)$. In the combined cohort of patients with idiopathic, familial and anorexigen-associated PAH, multivariable analysis showed that survival could be estimated by means of a novel riskprediction equation using patient sex, 6-min walk distance, and cardiac output at diagnosis.

This study highlights survivor bias in prevalent cohorts of PAH patients. Survival of idiopathic, familial and anorexigen-associated PAH can be characterised by means of a novel risk-prediction equation using patients' characteristics at diagnosis.

KEYWORDS: Exercise, mortality, pulmonary arterial hypertension, risk factors, sex

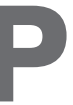
ulmonary arterial hypertension $(\mathrm{PAH})$ is a rare and severe condition defined as mean pulmonary arterial pressure $\geqslant 25 \mathrm{mmHg}$ at rest and pulmonary artery wedge pressure $\leqslant 15 \mathrm{mmHg}$, in the absence of other disorders such as chronic thromboembolic disease or chronic respiratory diseases and/or hypoxaemia [1-5]. PAH is characterised by remodelling of the small pulmonary arteries, resulting in a progressive increase in pulmonary vascular resistance leading to right ventricular failure and death [15]. Besides idiopathic and familial cases, PAH can be associated with conditions such as connective tissue disease, or develop as a consequence of drug or toxin exposure (e.g. anorexigens) [2, 5]. Patients with idiopathic, familial or anorexigenassociated PAH exhibit similar clinical, functional and haemodynamic characteristics, as well as overall survival. Different clinical outcomes have been observed, however, among patients with $\mathrm{PAH}$ associated with other underlying diseases [5-15].
Data describing the natural history of idiopathic and familial PAH were derived from a 1980 s National Institutes of Health (NIH)-supported registry in the USA [16]. A dismal median survival of 2.8 yrs following diagnosis was reported for this cohort [17]. Based on estimates obtained from proportional hazards models, an equation (the "NIH equation") was devised to predict a patient's likelihood of survival according to baseline haemodynamic measurements [17]. This method has since been widely used as a comparator in survival analyses [18-23]. However, the management of $\mathrm{PAH}$ has advanced significantly since the publication of the $\mathrm{NIH}$ registry. In particular, a more extensive assessment of patients using objective parameters is now routine and novel medical therapies have become available [2, 23]. Whilst survival among patients with idiopathic, familial and anorexigen-associated PAH has improved in comparison with historical estimates, recent studies indicate that $\mathrm{PAH}$ nonetheless remains a progressive, fatal disease despite these advances [22, 23].
AFFILIATIONS

A full list of the authors' affiliations and French Pulmonary Arterial Hypertension Network members and their affiliations can be found in the Acknowledgements.

\section{CORRESPONDENCE}

M. Humbert

Service de Pneumologie et

Réanimation Respiratoire

Hôpital Antoine Béclère

Assistance-Publique-Hôpitaux de

Paris

Université Paris-Sud 11

157 rue de la Porte de Trivaux 92140 Clamart

France

E-mail: marc.humbert@abc.aphp.fr

Received:

April 132010

Accepted after revision:

June 062010

First published online:

June 182010 
In the present study, we describe the entire cohort of 674 consecutive adult PAH patients enrolled in 2002-2003 in the French PAH Registry [24], with an emphasis on incident and prevalent cohorts of patients with idiopathic, familial and anorexigen-associated PAH (in order to eliminate survival bias due to comorbidities in subjects with associated conditions). In addition, we show that survival of idiopathic, familial and anorexigen-associated PAH can be characterized by means of a novel risk-prediction equation using patients' characteristics at diagnosis.

\section{METHODS}

The French Pulmonary Arterial Hypertension Network has been previously described [23, 24]. It was opened in 2002 in 17 pulmonary vascular university centres. For the purposes of this study, we evaluated all patients recruited between October 2002 and October 2003. This cohort was then prospectively followed for 3 yrs [23]. The registry is in compliance with requirements of the French Commission Nationale de l'Informatique et des Libertés, and all patients provided written informed consent to participate [23, 24].

PAH was defined as a mean pulmonary arterial pressure $\geqslant 25 \mathrm{mmHg}$ at rest and a pulmonary artery wedge pressure $\leqslant 15 \mathrm{mmHg}$, measured during right-heart catheterisation [2, $23,24]$. In order to ensure a homogeneous study population, patients with evidence of severe obstructive or restrictive ventilatory defects (defined as reduction to $<60 \%$ in measures of forced vital capacity, total lung capacity, or forced expiratory volume in $1 \mathrm{~s}$ ) or those with pulmonary hypertension secondary to other known chronic respiratory disease and/or hypoxaemia [5] were excluded.

PAH was classified as idiopathic, familial or associated with anorexigen exposure, connective tissue disease, portal hypertension, HIV infection and congenital heart disease [2, 5]. Incident cases were defined as patients diagnosed with $\mathrm{PAH}$ by rightheart catheterisation during the recruitment phase of the study (October 2002-October 2003) [23, 24]. Prevalent cases were defined as patients in whom the diagnosis was made prior to the start of the study $[23,24]$. Date of diagnosis was established as the date of confirmatory right-heart catheterisation [23, 24].

There was no mandatory specific treatment algorithm employed. Use of targeted therapies, including prostacyclin derivatives, endothelin receptor antagonists and phosphodiesterase type- 5 inhibitors was at the discretion of treating clinicians at each centre, according to current guidelines [23, 25, 26] and availability (in France, epoprostenol, bosentan, iloprost, and sildenafil were approved for PAH in March 1998, May 2002, September 2003 and October 2005, respectively).

\section{Survival analysis}

Patients who underwent lung transplantation were censored at the time of the operation. Patients lost to follow-up were censored at the time of their last clinic visit. Since cause of death could not always be confidently ascribed, all-cause mortality was used for analyses. Patients were followed prospectively after inclusion in the study and right-censored at 3 yrs.

We first described 1-, 2-, and 3-yr survival in the general population of $674 \mathrm{PAH}$ patients, with a focus on $\mathrm{PAH}$ subtypes, and incident and prevalent patients with idiopathic, familial, and anorexigen-associated PAH. In a subsequent analysis, data from the incident population with idiopathic, familial and anorexigenassociated PAH was combined with that from prevalent patients who were diagnosed $<3$ yrs prior to study entry (combined analysis population), as previously described [23]. In order to remove survivor bias that results from the inclusion of prevalent patients, survival estimates and a Cox proportional hazards model from time to diagnosis were adjusted for the left truncation arising from the delay between diagnosis and study entry. Patients were only in the risk set from their time of study entry; e.g. a patient recruited $1 \mathrm{yr}$ after diagnosis and followed for a further 3 yrs was considered to enter the risk set at 12 months and was right-censored at 36 months (i.e. 24 months from study entry). Kaplan-Meier analysis was used to estimate survival from time of diagnosis to 3 yrs post-diagnosis. We examined the relationship between potential prognostic variables measured at diagnostic catheterisation and mortality in the combined analysis population. All methods have been described elsewhere [23]. Statistical analyses were performed using SAS software (version 9.1; SAS Institute, Cary, NC, USA) [23].

In order to forecast post-diagnosis survival for an individual patient, a novel risk-prediction equation was developed, similar to the NIH registry model [16]. Baseline survival obtained via the multivariate Cox proportional hazards model was modelled via a weighted, nonlinear regression analysis, where baseline survival was:

$$
\mathrm{H}(t)=\exp (a+b \times t)
$$

where $a$ and $b$ are parameters estimated from the multivariate Cox proportional hazards model, and $t$ is the time from diagnosis measured in yrs. The predicted survival of a patient at $t$ is described by the equation:

$$
\mathrm{P}(t ; x, y, z)=\mathrm{H}(t)^{\mathrm{A}(x, y, z)}
$$

Here, $\mathrm{A}(x, y, z)$ is a function also obtained from the same Cox proportional hazards model, where $x$ is the distance walked (m) at diagnosis, $y=1$ if female, $y=0$ if male, and $z$ is the cardiac output $\left(\mathrm{L} \cdot \mathrm{min}^{-1}\right)$ at diagnosis. The functional form is:

$$
\mathrm{A}(x, y, z)=\exp (-(c \times x+d \times y+e \times z))
$$

where $c, d$, and $e$ were parameters obtained from the model. Thus, given the presentation of a patient with certain demographic and functional characteristics, a clinician may use this model to predict an individual patient's survival from 6 months up to 3 yrs post-diagnosis.

\section{RESULTS}

Descriptive analysis of survival from study entry in a cohort of 674 incident and prevalent PAH patients

674 consecutive adult patients were prospectively enrolled, corresponding to 121 incident and 553 prevalent cases [24] Idiopathic, familial, anorexigen-induced $\mathrm{PAH}$, connective tissue disease, congenital heart disease, portal hypertension and HIV infection-associated PAH accounted for 39.2\%, 3.9\%, $9.5 \%, 15.3 \%, 11.3 \%, 10.4 \%$ and $6.2 \%$ of the population, respectively (fig. 1) [24]. Notably, $4.3 \%$ of patients had two coexisting risk factors. Among patients with connective tissue disease, the majority displayed systemic sclerosis (72\%). Baseline characteristics of this population have been described previously [24]. 
In the general population $(n=674), 1-, 2-$, and 3-yr survival rates after study entry were $87 \%$ (95\% CI $84-90), 76 \%$ (95\% CI 73-80), and 67\% (95\% CI 63-71), respectively (fig. 2a). Better survival was observed in females (fig. 3a), as well as in younger patients (age $\leqslant 51$ years) (fig. $3 b$ ) and in patients in New York Heart Association (NYHA) functional class (FC) I or II (fig. 3c). Survival was also better in the prevalent cohort, as compared to the incident one: in the prevalent cohort, 1-, 2-, and 3-yr survival rates were 88\% (95\% CI 85-91), 79\% (95\% CI $75-82)$, and $71 \%$ (95\% CI 67-74), as compared to $88 \%(95 \% \mathrm{CI}$ $80-93), 65 \%(95 \%$ CI 56-74), and 51\% (95\% CI 42-60) in the incident cohort, respectively $(\mathrm{p}<0.0001)$. In addition, survival differed according to co-morbidities. Better 3-year survival rates were observed in patients with congenital heart disease, whilst the cohort with connective tissue disease had worse survival, highlighting the influence of associated conditions on PAH outcomes (fig. 2b).

Similar survival rates were observed in patients with idiopathic, familial or anorexigen-associated $\mathrm{PAH}$, highlighting the relevance of grouping these three subcategories together (data not shown). In prevalent idiopathic, familial and anorexigenassociated PAH, 1-, 2-, and 3-yr survival rates were 89\% (95\% CI $86-93), 77 \%$ (95\% CI 73-82), and 69\% (95\% CI $63-74)$ (fig. 4a). This was higher than in incident patients who were characterised by 1-, 2-, and 3-yr survival rates of $89 \%(95 \% \mathrm{CI}$ 78-97), 68\% (95\% CI 55-81), and 55\% (95\% CI 42-68) (p=0.037) (fig. 4a). Interestingly, analysis of survival from study entry according to quartiles of time from diagnosis revealed better survival in prevalent patients with longer duration of disease prior to inclusion in the study (fig. $4 \mathrm{~b}$ ). In summary, PAH prevalent cohorts had significantly better outcomes than incident cohorts (fig. 4a).

\section{A novel equation predicting survival from diagnosis in a combined population of 190 prevalent and incident cases with idiopathic, familial and anorexigen-associated PAH}

Because outcomes were markedly influenced by the presence or absence of associated conditions, we focused our next analysis on the incident cohort of patients with idiopathic, familial and anorexigen-associated PAH. As previously discussed, we grouped the 56 incident cases together with those 134 prevalent patients who were diagnosed $<3$ yrs prior to study entry $(n=190)$ [23]. Treatments at study inclusion in the combined population of patients with idiopathic, familial or anorexigen-associated PAH have been described elsewhere [23]. Briefly, at study entry, medical management consisted solely of conventional therapy in $29.5 \%$ of patients, corresponding mostly to acute vasodilator responders who benefited from first-line calcium channel blocker therapy, patients in NYHA FC II or patients who died prematurely before any specific therapy was initiated. Targeted therapies were epoprostenol in $14.7 \%$, other prostacyclin derivatives in $5.2 \%$, endothelin receptor antagonists in 35.3\%, type 5 phosphodiesterase inhibitors in $2.1 \%$ and a combination of these therapies in $12.6 \%$. Modifications or combinations of targeted therapies were proposed over the 3-yr period at the discretion of treating clinicians at each centre. Survival estimates of this combined cohort have been detailed elsewhere [23]. Briefly, 1-, $2-$, and 3-yr survival was 83\% (95\% CI 72-95), 67\% (95\% CI 5779 ) and 58\% (95\% CI 49-69), and multivariable analysis indicated a significantly improved survival rate among females and those with higher measures of 6-min walk distance (6MWD) and cardiac output [23].

Applying the post-diagnosis survival prediction method, the baseline survival was estimated as:

$$
\mathrm{H}(t)=\exp (-0.02-0.28 t)
$$

where $t$ corresponds to number of yrs since diagnosis. The multivariate Cox proportional hazards model gave parameter estimates such that:

$$
\mathrm{A}(x, y, z)=\exp (-(0.004 x+0.98 y+0.28 z))
$$

where $x$ is 6MWD at diagnosis $-280 \mathrm{~m}, y=1$ if female, $y=0$ if male and $z$ is cardiac output at diagnosis $-4.0 \mathrm{~L} \cdot \mathrm{min}^{-1}$ ). Therefore, the estimated survival of a patient at $t$ yrs postdiagnosis is:

$$
\begin{aligned}
\mathrm{P}(t ; x, y, z) & =\mathrm{H}(t)^{\mathrm{A}(x, y, z)} \\
& =\exp (-0.02-0.28 t)^{\exp (-(0.004 x+0.98 y+0.28 z))}
\end{aligned}
$$

For example, in a female who presents with a 6MWD of $200 \mathrm{~m}$ and a cardiac output of $3 \cdot 2 \mathrm{~L} \cdot \mathrm{min}^{-1}$ at diagnosis, the equation generates:

$$
\begin{aligned}
\mathrm{A}(200,1,3.2)= & \exp (-(0.004 \times(200-280)+ \\
& 0.98 \times 1+0.28 \times(3.2-4.0))) \\
= & 0.647
\end{aligned}
$$

Baseline survival at year 2 is estimated as:

$$
\begin{aligned}
\mathrm{H}(2) & =\exp (-0.02-0.28 \times 2) \\
& =0.560
\end{aligned}
$$

Therefore, this patient's estimated survival 2 yrs post-diagnosis is:

$$
\begin{aligned}
\mathrm{P}(2 ; 200,1,3.2) & =\mathrm{H}(2)^{\mathrm{A}(200,1,3.2)} \\
& =0.560^{0.647} \\
& =0.69
\end{aligned}
$$

or $69 \%$.

\section{DISCUSSION}

The present study shows that survival in patients with $\mathrm{PAH}$ is influenced by several factors. Although highly relevant baseline clinical characteristics are strong determinants of outcome, estimation of survival is also subject to several biases, including presence of associated conditions and interval from diagnosis to study enrolment. This strongly suggests that analysis of incident cohorts of homogeneous PAH populations should be recommended in future survival studies.

As previously described, associated conditions may dramatically influence survival rates in PAH cohorts [5-14]. Our results confirm that patients with PAH complicating the course of congenital heart disease are more likely to survive to 3 yrs compared to patients that develop PAH in the setting of connective tissue diseases, such as systemic sclerosis, despite similar management approaches $[5,9,10]$. Therefore, we recommend that PAH cases with associated conditions (e.g. connective tissue disease, portal hypertension, HIV infection and congenital heart disease), should 


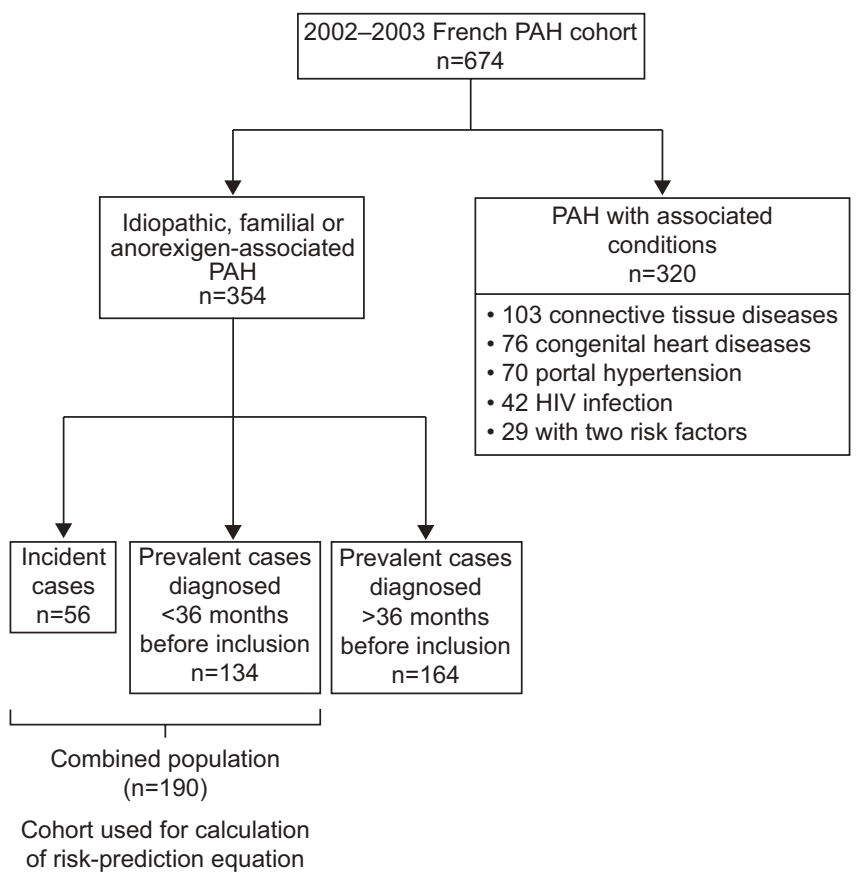

FIGURE 1. Study design. PAH: pulmonary arterial hypertension.

not be merged with patients having isolated pulmonary vascular disease (such as idiopathic PAH) in future survival analysis. In accordance with this statement, we focused our present study on patients with idiopathic, familial and anorexigen-associated $\mathrm{PAH}$, i.e. aetiologies with similar outcomes that share clinical and genetic characteristics [9-11].

Another survivor bias confirmed in our analyses is the interval between time of diagnosis and study recruitment. We clearly show that survival of incident cohorts is poorer than that of

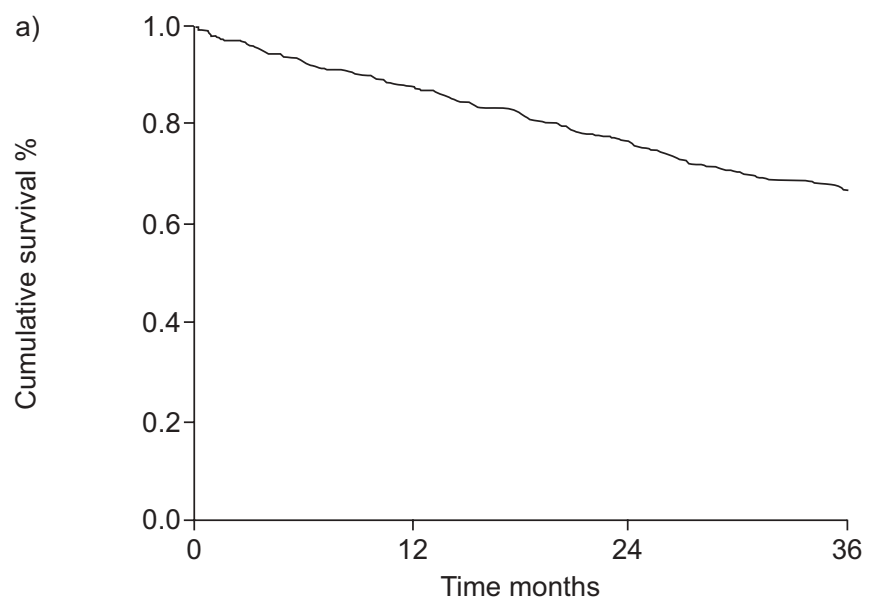

Subjects $n$

French 674

PAH cohort

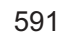

517

458

Subjects $n$

$\begin{array}{lc}\text { Idiopathic } & 354 \\ \text { PAH } & \\ \text { CTD PAH } & 103 \\ \text { CHD PAH } & 76\end{array}$

b) prevalent cohorts and that better survival is observed in prevalent patients with longer duration of disease prior to inclusion in the study. This information has important consequences, as many patients enrolled in randomised trials of investigational therapies are characterised by stable prevalent disease, suggesting a major survivor bias when long-term survival is described in such clinical trials or their long-term extensions [20, 21, 27]. In this regard, the better outcomes of prevalent populations may relate to the enrichment of such studies with patients that have better right ventricular function (i.e. patients with marked and progressive right-heart failure are more likely to die early and, thus, be underrepresented in late prevalent cohorts) and/or patients with better response to PAH management (i.e. patients with refractory PAH will die or will be transplanted earlier). Further studies are needed to better understand the reasons for the better prognosis observed in prevalent PAH cohorts.

In incident $\mathrm{PAH}$ patients with idiopathic, familial or anorexigenassociated $\mathrm{PAH}$, independent predictors of survival included female sex, greater 6MWD and higher cardiac output [23]. Whilst this study was not designed to compare treatment strategies with the previous management era described at the time of the $\mathrm{NIH}$ registry, we nevertheless observed that, despite novel therapeutic strategies, $\mathrm{PAH}$ remains a progressive and fatal disease [23]. In addition, we generated an equation that may be useful in predicting survival in an incident population of idiopathic, familial and anorexigen-associated PAH treated in the modern management era. However, our proposed new formula needs to be validated in an independent patient population in order to establish its reliability and its generalisability to populations different to that in the current study. Since recent pulmonary hypertension guidelines now advocate a more aggressive management approach, including early treatment of mildly symptomatic NYHA FC II patients and use of sequential combination therapies in those who do not reach predefined treatment goals, it would be interesting to study survival trends

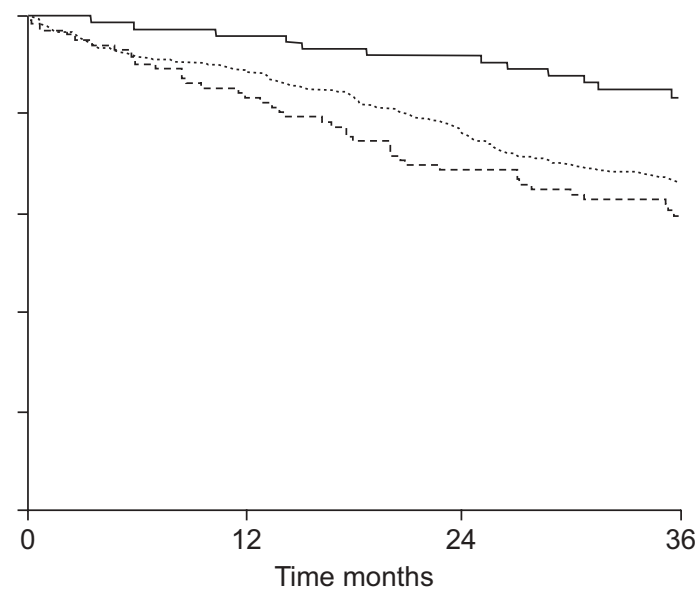

FIGURE 2. a) 3-yr survival of the entire cohort of 674 pulmonary arterial hypertension (PAH) patients. b) 3-yr survival in PAH patients with congenital heart disease (CHD; $\longrightarrow$, idiopathic PAH (..........) or connective tissue disease (CTD; ------); $\mathrm{p}<0.05$. 


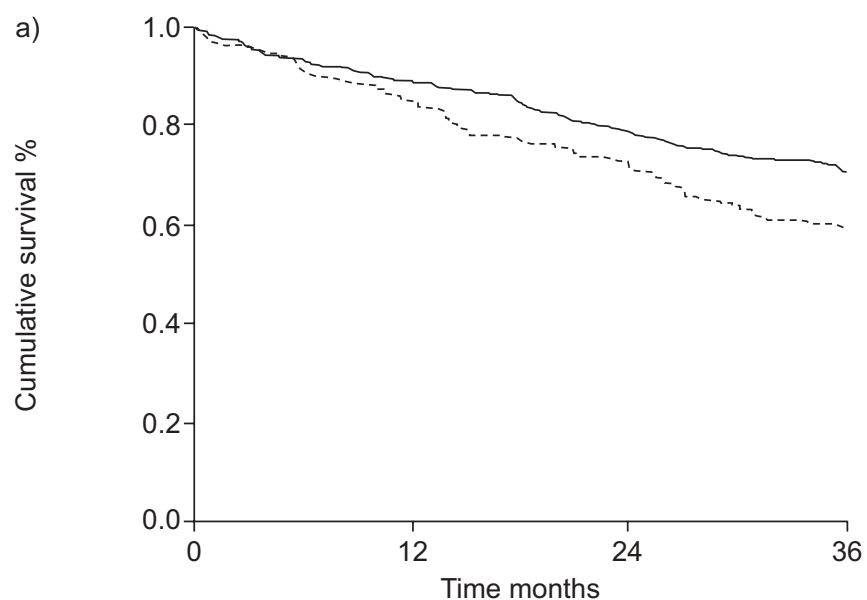

Subjects $n$

$\begin{array}{lllll}\text { Female } & 440 & 392 & 348 & 316 \\ \text { Male } & 234 & 199 & 169 & 142\end{array}$

c)

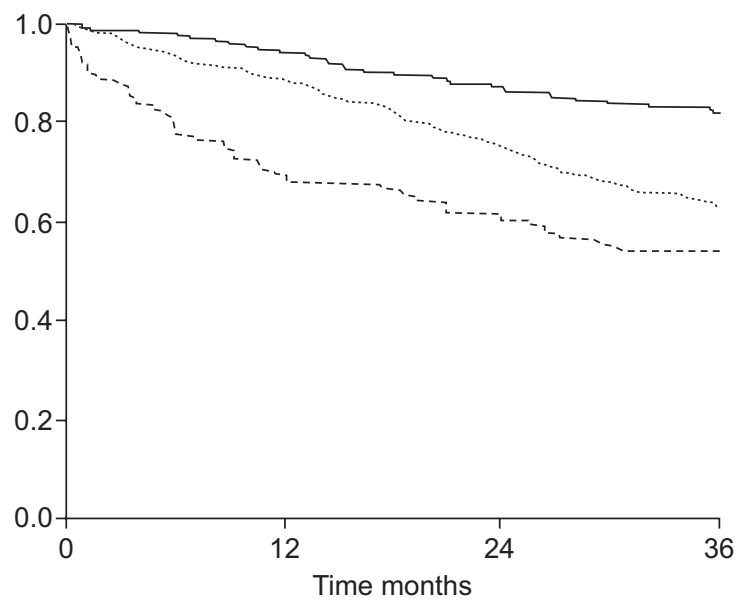

Subjects $\mathrm{n}$

$\begin{array}{lcccc}\text { NYHAFC } & 172 & 163 & 152 & 144 \\ \text { I/II } & & 374 & 317 & 271 \\ \begin{array}{l}\text { NYHA FC } \\ \text { III }\end{array} & 421 & 54 & 48 & 43 \\ \begin{array}{l}\text { NYHA FC } \\ \text { IV }\end{array} & 81 & & & \end{array}$

IV

in more recent cohorts [2]. The present study considers survival among patients with a rare disease at a national level in 20022006. Obviously, with more data or events we could make more accurate estimates of predicted survival. We consider that our work represents a worthy addition to this scientific field but should be considered as hypothesis-generating, not hypothesisconfirming. While survival estimates can be calculated for a given patient, as proposed in our manuscript, one must emphasise that our equation simply reflects outcomes in a cohort of patients managed in France in 2002-2006 and that the risk-prediction equation has obvious limitations when one attempts to predict outcomes of a given individual.

PAH mortality is most closely associated with male sex, right ventricular haemodynamic function and exercise limitation [23]. An improved understanding of the influence of sex on $\mathrm{PAH}$ development and outcomes is, therefore, of critical b)

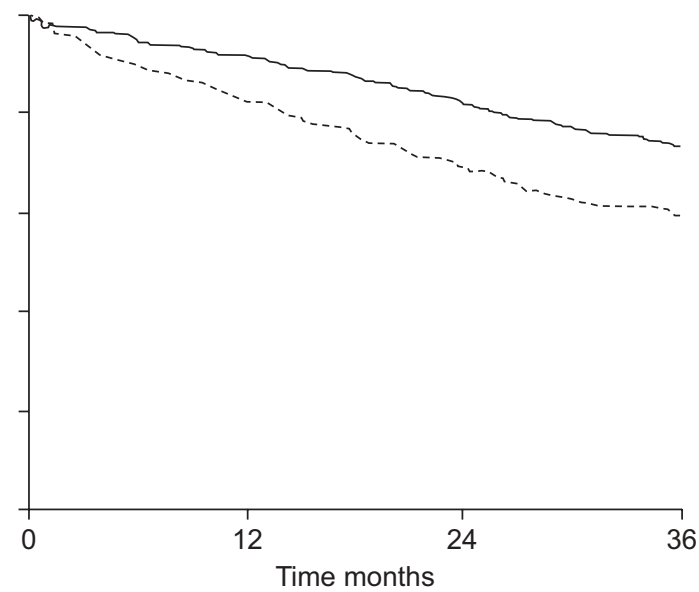

Subjects $n$

$\begin{array}{lllll}\text { Age }>51 \text { yrs } & 324 & 268 & 227 & 196\end{array}$

$\begin{array}{llll}\text { Age } \leq 51 \text { yrs } 350 & 322 & 289\end{array}$
FIGURE 3. a) 3-yr survival of the entire cohort of 674 pulmonary arterial hypertension (PAH) patients, according to sex. - : females; ---: males. $p<0.001$. b) 3-yr survival of the entire cohort of $674 \mathrm{PAH}$ patients, according to age at study entry. - $: \leqslant 51$ yrs; -----: $>51$ yrs. $p<0.001$ c) 3-yr survival of the entire cohort of $674 \mathrm{PAH}$ patients, according to New York Heart Association functional class (FC) at study entry. — : FC I/II; .......... FC III; ------: FC IV. $p<0.001$.

importance. PAH is a disease with an undisputed female predominance, suggesting that hormonal influences promote the development of pulmonary vascular remodelling in predisposed individuals (as strongly suggested by the female PAH predominance even in patients carrying a BMPR2 mutation). Nevertheless, our study shows that male sex is associated with poorer survival $[6,15,23,24]$. These sex-related characteristics deserve further attention and it would be timely to support research programmes attempting to understand the influence of sex on disease occurrence and outcomes [28].

Our analysis has several limitations. First, our risk-prediction equation focused on a homogeneous patient population with idiopathic, familial and anorexigen-associated PAH, and therefore it cannot be readily generalised to patient groups with $\mathrm{PAH}$ associated with other diseases. In addition, our study was performed at a time when several currently available therapies 


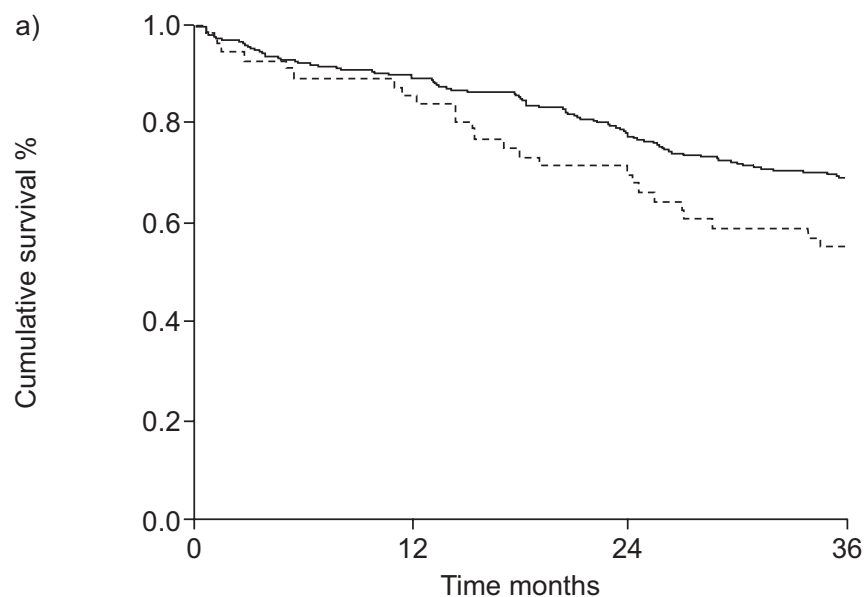

Subjects $\mathrm{n}$

$\begin{array}{lcccc}\text { Incident } & 56 & 48 & 39 & 29 \\ \text { Prevalent } & 298 & 263 & 222 & 192\end{array}$

b)

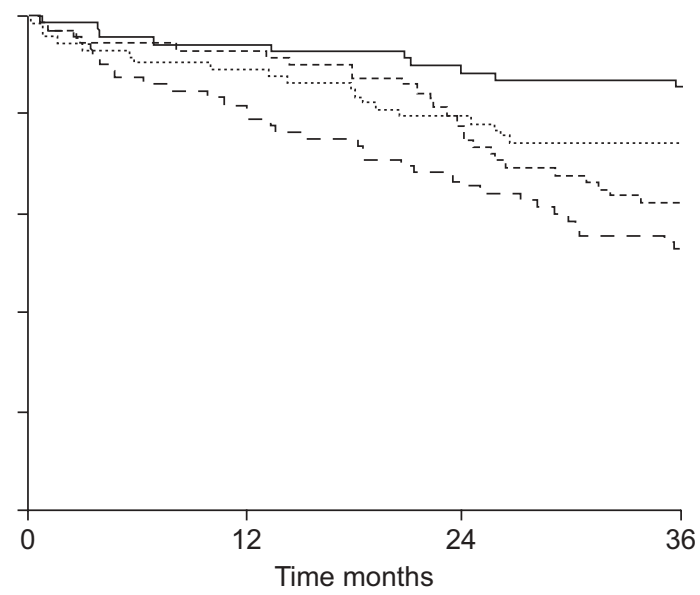

Subjects $n$

$\begin{array}{lllll}\geq 80 \text { months } & 74 & 68 & 61 & 58 \\ \begin{array}{l}40-80 \\ \text { months }\end{array} & 75 & 66 & 59 & 52 \\ \begin{array}{l}16-40 \\ \text { months }\end{array} & 74 & 68 & 54 & 43 \\ <16 \text { months } & 75 & 59 & 48 & 39\end{array}$

FIGURE 4. a) 3-yr survival from study entry of incident (-----) and prevalent (-) patients with idiopathic, familial and anorexigen-associated pulmonary arterial hypertension. b) Survival from study entry according to quartiles of time from diagnosis in the prevalent population. ——: $>80$ months; $\cdots \cdots \cdots \cdots . . .40-80$ months; ------: $16-$ 40 months; - - - - : $<16$ months. $p<0.001$.

were not yet available and in the context of treatment guidelines that advocated a relatively less aggressive treatment approach [23-26]. These factors may have negatively affected outcomes in some patients who would be likely to be treated more aggressively in the current management era [2]. In addition, we analysed patients treated in selected centres with expertise in pulmonary vascular medicine and may, therefore, have focused on a subset of patients with severe disease. However, as PAH care in France is performed by a network of selected sites associated with the French National Referral Centre [23, 24], our results presumably represent the prevailing status of $\mathrm{PAH}$ management and outcomes at the time of our study (2002-2006). The selection of a robust outcome measure (survival) in a population without comorbid conditions is a strength of this multicentre, nationwide study. It is important to note, however, that the population used to generate the risk-prediction equation in our study is rather small (190 patients with 53 deaths in $3 \mathrm{yrs}$ ), thereby limiting the identification of potentially strong risk factors. Thus, the prediction equation derived from this sample might over- or underestimate survival in other PAH samples. In an attempt to validate our risk-prediction equation, we are currently testing our proposed new formula in an independent patient population.

In conclusion, our results indicate that PAH remained a severe, life-threatening disease at the start of the last decade, despite better awareness and improved management. Recent guidelines now recommend more active treatment strategies, including systematic referral to expert centres, early management with specific therapies in symptomatic $\mathrm{PAH}$ patients as early as NYHA FC II and use of sequential combination therapies when ambitious treatment goals are not met [2]. The impact on patient outcome of this therapeutic paradigm shift is the focus of an ongoing study evaluating a new cohort selected from our national network. In any case, the current analysis clearly emphasises the need for additional research and discoveries in the field of PAH in order to improve outcomes for those with this dismal disease.

\section{SUPPORT STATEMENT}

D. S. O'Callaghan is the recipient of a European Respiratory Society Fellowship number 67.

\section{STATEMENT OF INTEREST}

Statements of interest for all authors can be found at www.erj. ersjournals.com $/ \mathrm{misc} /$ statements.dtl

\section{ACKNOWLEDGEMENTS}

M. Humbert, O. Sitbon, A. Yaïci, D. Montani, D. S. O'Callaghan, X. Jaïs, F. Parent, L. Savale, D. Natali, S. Günther and G. Simonneau: Université Paris-Sud, Faculté de Médecine, Clamart, France; AP-HP, Centre National de Référence de l'Hypertension Pulmonaire Sévère, Service de Pneumologie et Réanimation Respiratoire, Hôpital Antoine Béclère, Clamart, France; INSERM U999, Hypertension Artérielle Pulmonaire: Physiopathologie et Innovation Thérapeutique, IPSIT, Centre Chirurgical Marie-Lannelongue, Le Plessis-Robinson, France. A. Chaouat: Service de Pneumologie, Hôpital Hautepierre, Strasbourg, France; Service de Pneumologie, Hôpital de Brabois, Vandoeuvre-les-Nancy, France. F. Chabot: Service de Pneumologie, Hôpital de Brabois, Vandoeuvre-les-Nancy, France. J-F. Cordier: Service de Pneumologie, Hôpital Louis-Pradel, Lyon, France. G. Habib: Service de Cardiologie, Hôpital de la Timone, Marseille, France. V. Gressin: Actelion Pharmaceuticals France, Paris. Z-C. Jing: Université Paris-Sud, Faculté de Médecine, Clamart, France; AP-HP, Centre National de Référence de l'Hypertension Pulmonaire Sévère, Service de Pneumologie et Réanimation Respiratoire, Hôpital Antoine Béclère, Clamart, France; INSERM 
U999, Hypertension Artérielle Pulmonaire: Physiopathologie et Innovation Thérapeutique, IPSIT, Centre Chirurgical Marie-Lannelongue, Le Plessis-Robinson, France; Dept of Pulmonary Circulation, Shanghai Pulmonary Hospital, Tongji University School of Medicine, Shanghai, China. R. Souza: Université Paris-Sud, Faculté de Médecine, Clamart, France; AP-HP, Centre National de Référence de l'Hypertension Pulmonaire Sévère, Service de Pneumologie et Réanimation Respiratoire, Hôpital Antoine Béclère, Clamart, France; INSERM U999, Hypertension Artérielle Pulmonaire: Physiopathologie et Innovation Thérapeutique, IPSIT, Centre Chirurgical Marie-Lannelongue, Le Plessis-Robinson, France; Pulmonary Dept, Heart Institute, University of São Pãulo Medical School, São Pãulo, Brazil.

The following investigators also contributed to the conduct and reporting of this study: I. Enache, E. Weitzenblum (both Hôpital Hautepierre, Strasbourg, France), M. Bertocchi, B. Mastroianni, V. Cottin, J.-F. Mornex (all Hôpital Louis-Pradel, Lyon, France), C. Dromer, J. Constans (both Hôpital du Haut-Levesque, Purpan, France), N. Beuraud, (Hôpital de Brabois, Vandoeuvre-les-Nancy, France), M. Laurent, C. Almange (both Hôpital Pontchaillou, Rennes, France), C. Pison, C. Saunier, H. Bouvaist, C. Saint Raymond (all Hôpital Michallon, Grenoble, France), S. Renard, M. Reynaud-Gaubert (both Hôpital de la Timone and Hôpital Sainte-Marguerite Marseille, France), E. Hachulla, B. Wallaert (both Hôpital Claude Huriez, Lille, France), A. Haloun (Hôpital Laennec, Nantes, France), I. Frachon (Hôpital de la Cavale Blanche, Brest, France), J. Inamo (Hôpital de Fort de France, France), R. Escamilla, B. Degano (both Hôpital Purpan, Toulouse, France), B. Melloni (Hôpital de Limoges, France), L. Guillevin and L. Mouthon (both Hôpital Cochin, Paris, France).

The authors thank the patients who kindly participated in this study. The authors warmly thank S. Souza (University of São Pãulo Medical School, São Pãulo, Brazil), A. Muller and D. Rosenberg (Actelion Pharmaceuticals Ltd., Allschwil, Switzerland) for their expert support in statistical analysis. The authors also thank M. Childs, G. Taquoi, Y. Kleiman, and F. Quéré (Médiscan, Paris, France) for their support in managing the project and ensuring data management and statistics.

\section{REFERENCES}

1 McLaughlin VV, McGoon MD. Pulmonary arterial hypertension. Circulation 2006; 114: 1417-1431.

2 Galiè N, Hoeper MM, Humbert M, et al. Guidelines for the diagnosis and treatment of pulmonary hypertension. Eur Respir $J$ 2009; 34: 1219-1263.

3 Humbert M, Morrell NW, Archer SL, et al. Cellular and molecular pathobiology of pulmonary arterial hypertension. J Am Coll Cardiol 2004; 43: 13S-24S.

4 Farber HW, Loscalzo J. Pulmonary arterial hypertension. N Engl J Med 2004; 351: 1655-1665.

5 Simonneau G, Robbins I, Beghetti M, et al. Updated clinical classification of pulmonary hypertension. J Am Coll Cardiol 2009; 54: S43-S54.

6 Sztrymf B, Coulet F, Girerd B, et al. Clinical outcomes of pulmonary arterial hypertension in carriers of BMPR2 mutation. Am J Respir Crit Care Med 2008; 177: 1377-1383.

7 Girerd B, Montani D, Coulet F, et al. Clinical outcomes of pulmonary arterial hypertension in patients carrying an ACVRL1 (ALK1) mutation. Am J Respir Crit Care Med 2010; 181: 851-861.

8 Souza R, Humbert M, Sztrymf B, et al. Pulmonary arterial hypertension associated with fenfluramine exposure: report of 109 cases. Eur Respir J 2008; 31: 343-348.

9 Dimopoulos K, Inuzuka R, Goletto S, et al. Improved survival among patients with Eisenmenger syndrome receiving advanced therapy for pulmonary arterial hypertension. Circulation 2010; 121: 20-25.

10 Le Pavec J, Humbert M, Mouthon L, et al. Systemic sclerosisassociated pulmonary arterial hypertension. Am J Respir Crit Care Med 2010; 181: 1285-1293.

11 Le Pavec J, Souza R, Herve P, et al. Portopulmonary hypertension: survival and prognostic factors. Am J Respir Crit Care Med 2008; 178: 637-643.

12 Degano B, Guillaume M, Savale L, et al. HIV-associated pulmonary arterial hypertension: survival and prognostic factors in the modern therapeutic era. AIDS 2010; 24: 67-75.

13 Fernandes CJCS, Jardim C, Hovnanian A, et al. Survival in schistosomiasis associated pulmonary arterial hypertension. J Am Coll Cardiol 2010; [Epub ahead of print DOI: 10.1016/ j.jacc.2010.03.065].

14 Gladwin MT, Sachdev V, Jison ML, et al. Pulmonary hypertension as a risk of death in patients with sickle cell disease. $N$ Engl J Med 2004; 350: 886-895.

15 Rich S, Danzker DR, Ayres SM, et al. Primary pulmonary hypertension: a national prospective study. Ann Int Med 1987; 107: 216-223.

16 D'Alonzo GE, Barst RJ, Ayres SM, et al. Survival in patients with primary pulmonary hypertension. Ann Int Med 1991; 115: 343-349.

17 McLaughlin VV, Shillington A, Rich S. Survival in primary pulmonary hypertension: the impact of epoprostenol therapy. Circulation 2002; 106: 1477-1782.

18 Sitbon $\mathrm{O}$, Humbert M, Nunes $\mathrm{H}$, et al. Long-term intravenous epoprostenol infusion in primary pulmonary hypertension: prognostic factors and survival. J Am Coll Cardiol 2002; 40: 780-788.

19 Hoeper MM, Gall H, Seyfarth HJ, et al. Long-term outcome with intravenous iloprost in pulmonary arterial hypertension. Eur Respir J 2009; 34: 132-137.

20 McLaughlin VV, Sitbon O, Badesch DB, et al. Survival with firstline bosentan in patients with primary pulmonary hypertension. Eur Respir J 2005; 25: 244-249.

21 Barst RJ, Galie N, Naeije R, et al. Long-term outcome in pulmonary arterial hypertension patients treated with subcutaneous treprostinil. Eur Respir J 2006; 28: 1195-1203.

22 Thenappan T, Shah SJ, Rich S, et al. Contemporary survival in patients with pulmonary arterial hypertension: a reappraisal of the National Institutes of Health Risk Stratification Equation. Eur Respir J 2010; 35: 1079-1089.

23 Humbert M, Sitbon O, Chaouat A, et al. Survival in patients with idiopathic, familial, and anorexigen-associated pulmonary arterial hypertension in the modern management era. Circulation 2010; 122: 156-163.

24 Humbert M, Sitbon O, Chaouat A, et al. Pulmonary arterial hypertension in France: results from a national registry. Am J Respir Crit Care Med 2006; 173: 1023-1030.

25 Humbert M, Sitbon O, Simonneau G. Treatment of pulmonary arterial hypertension. $N$ Engl J Med 2004; 351: 1425-1436.

26 Sitbon O, Humbert M, Simonneau G. Treatment for pulmonary arterial hypertension under the new French hospital financing system: recommendations of the Pulmonary Vascular Diseases Working Group of the French Society of Pulmonary Medicine. Presse Med 2005; 34: 1456-1464.

27 Galiè N, Manes A, Negro L, et al. A meta-analysis of randomized controlled trials in pulmonary arterial hypertension. Eur Heart J 2009; 30: 394-403.

28 Austin ED, Cogan JD, West JD, et al. Alterations in oestrogen metabolism: implications for higher penetrance of familial pulmonary arterial hypertension in females. Eur Respir J 2009; 34: 1093-1099. 